first discovered to be hypertensive two months before her myocardial infarction. The third patient was a single girl from the Continent who had taken oral contraceptives for three years. We have no previous medical records about her.

We do not consider that our report of 22 women under the age of 45 years with acute myocardial infarction represents "a small amount of inadequate information" upon which to base recommendations. It is the largest series yet assembled and we were particularly careful not to draw overemphatic conclusions.-We are, etc.,

D. J. RADFORD Department of Cardiology, M. F. OLIVER Royal Infirmary, Edinburgh

SIR,-In the introduction to the article by Drs. Dorothy J. Radford and M. F. Oliver (25 August, p. 428) references are cited to reports in which an association between oral contraception and the occurrence of myocardial infarction is claimed. One of the reports referred to is that by Hartveit ${ }^{1}$ which describes the case of a 32-year-old woman who died in Bergen, Norway, in 1964, apparently of the consequences of myocardial infarction. The same case has also been described by Høsteng. ${ }^{2}$ References to both these $r$ ports can be found in a number of other, later articles.

As a result of legal proceedings directly concerned with this case I had the opportunity to study the case-notes thoroughly and also to re-examine the histological material. I subsequently came to the conclusion that this was not a case of myocardial infarction as a consequence of primary thrombosis but rather-and there were a number of positive indications to support my opinion-a case of chronic myocarditis accompanied by coronary arteritis, neuritis, and pericarditis. The heart was dilated with large areas of mottled yellow colour. Microscopical examination revealed pronounced and diffuse leucocyte infiltration with no border zones, including muscles, vessels, and nerves. A large number of scattered fibrous areas were found, all of them showing leucocyte infiltration. No coagulation necrosis was found; on the contrary, the nuclei of the muscle fibres were large and prominent.

In view of the foregoing I would suggest that there is no longer any justification for including the case described by Hartveit and Høsteng in lists of references on the subject of oral contraceptives and myocardial infarction.-I am, etc.,

Institutt for Patologi,

Rikshospitalet

Oslo

1 Hartveit, F., British Medical fournal, 1965, 1, 60. Hosteng, T. Oegerening, i965, 85, 1692.
Laefort

\section{Incidence of Idiopathic Venous Thromboembolism in Nurses}

SIR,-The interesting paper by Surgeon Lieutenant L. E. Ramsey and Surgeon Lieutenant-Commander M. A. MacLeod (24 November, p. 446) suggesting a high incidence of idiopathic venous thromboembolic disease among nurses requires a note of caution before alarm is spread within the nursing profession. In our experience clinical symptoms and signs do not lead to "a very low incidence of false positive diagnosis" of deep vein thrombosis (D.V.T.).

Over the past 21 months (March 1972November 1973) 37 women, including seven nurses, between the ages of 14 and 45 years have been referred to us with a clinical diagnosis of idiopathic D.V.T. Satisfactory ascending venograms were obtained in 35 patients, including all the nurses. Thrombosis was confirmed in only 11 cases (table I), indicating a false positive clinical diagnosis in nearly $\mathbf{7 0} \%$. When we applied the clinical criteria used by Drs. Ramsey and MacLeod for the diagnosis of idiopathic D.V.T. we were left with 26 cases; in only nine of these was thrombosis confirmed venographically, a false positive clinical diagnosis rate of $65 \%$.

TABLE I-Patients with Clinical Diagnosis of D.V.T

\begin{tabular}{|c|c|c|c|c|}
\hline \multirow{2}{*}{$\begin{array}{l}\text { D.V.T. } \\
\text { Clinical } \\
\text { Severity } \\
\text { Score }\end{array}$} & \multicolumn{2}{|c|}{ Nurses } & \multicolumn{2}{|c|}{ Others } \\
\hline & "Pill" & No "Pill" & "Pill" & No "Pill" \\
\hline $\begin{array}{l}1 \text { point } \\
2 \text { " }\end{array}$ & $\begin{array}{l}1(0) \\
5(0)\end{array}$ & 二 & $10 \overline{(2)}$ & $\begin{array}{l}2\left(1^{*}\right) \\
4\left(1^{*}\right)\end{array}$ \\
\hline $\begin{array}{ll}3 \quad \\
4 \quad\end{array}$ & $1(0)$ & $=$ & $\begin{array}{l}6(3) \\
7(6)\end{array}$ & $1(0)$ \\
\hline Total & $7(0)$ & - & $23(11)$ & $7\left(2^{*}\right)$ \\
\hline
\end{tabular}

Pain, tenderness, temperature difference between limbs, and pitting oedema each scored one point.

Figures in parentheses $=$ no. with positive venograms *=equivocal venograms).

We believe that most cases of D.V.T. occurring in this area are sent to the Radcliffe Infirmary and then referred to us. The estimated incidence (per thousand population per year) of idiopathic D.V.T. in women of child-bearing age in our catchment area is shown in table II. The calculations are based on information from the population records of the Oxford Regional Hospital Board-1,600 nurses (whole-time equivalents) and 88,500 others.

TABLE II-Estimated incidence $(/ 1,000 / y r)$ of D.V.T. in women of child-bearing age in the Oxford Area

\begin{tabular}{lll|c|c|c}
\hline Method of Diagnosis & Nurses & Others & Total \\
\hline Clinical &. & $\ldots$ & $\begin{array}{l}2.50 \\
0.00\end{array}$ & $\begin{array}{l}0.19 \\
0.07\end{array}$ & $\begin{array}{l}0.23 \\
0.07\end{array}$ \\
\hline
\end{tabular}

All seven nurses in whom the clinical diagnosis of D.V.T. had been made were taking the "pill" but none had a D.V.T. proved venographically. Of the 30 others, 23 $(77 \%)$ were on the "pill" and 11 of these had proved D.V.T. The clinical severity score (table I) was low ( 1 or 2 ) in six nurses; in the others the score tended to be higher (3 or 4) in those on the "pill" compared with those not on the "pill." The higher the score, the greater was the likelihood of a positive venogram.

These data suggest that nurses seek medical advice and are referred by their doctors even with relatively mild symptoms, which are not necessarily due to D.V.T. Part of the explanation for this may be that nurses and doctors are particularly aware of an association between D.V.T. and oral contraceptives. This does not appear to be the case in the general population, however, because women using oral contraceptives who were referred to us had notably more severe clinical disease than women not on oral contraceptives. A closely similar observation was made by Vessey and Doll. ${ }^{1}$ They found that the use of oral contraceptives was less frequent among those in whom the clinical diagnosis of D.V.T. was less certain. It is unlikely, therefore, that the observed association between D.V.T. and oral contraceptives is due to a greacer tendency to diagnose D.V.T. in users of oral contraceptives. Further positive support for an association between D.V.T. and oral contraceptives is provided by the fact that all the women in our series with venographically proven D.V.T. were using oral contraceptives.

In conclusion, we cannot agree that nursing predisposes to idiopathic venous thrombosis.-We are, etc.,

D. A. TIBbutT E. W. Williams

TIM FAULKNER

Radcliffe Infirmary,

1 Vessey, M. P., and Doll, R., British Medical fournal, 1968,' 2, 199.

\section{Aspiration of Thermometer Fragment}

SIR,-Among the most common measurements in medical practice is the recording of body temperature. This is considered a harmless procedure and only a very few accidents have been reported in this context. The implications of such an event can, however, be quite serious, which prompts us to report the following experience.

A 33-year-old white woman had an episode of sharp left flank pain lasting for about $\mathbf{4 5}$ minutes before presenting in the emergency department of our hospital. During the process of recording her oral temperature the patient had a seizure, fractured the thermometer, and aspirated part of it. It was later found out that she had had a long-standing seizure disorder. On physical examination the patient was in no acute distress and no significant findings were noted.

Chest radiographs revealed the proximal fragment of the thermometer in the right lower lobe (see fig.). On bronchoscopy it was seen firmly wedged in the medial basilar segmental bronchus of the right lower lobe and repeated attempts to remove it were unsuccessful. It was successfully removed, however, after thoracotomy and bronchotomy. The flank pain for which the patient sought help in the first instance did not recur while the

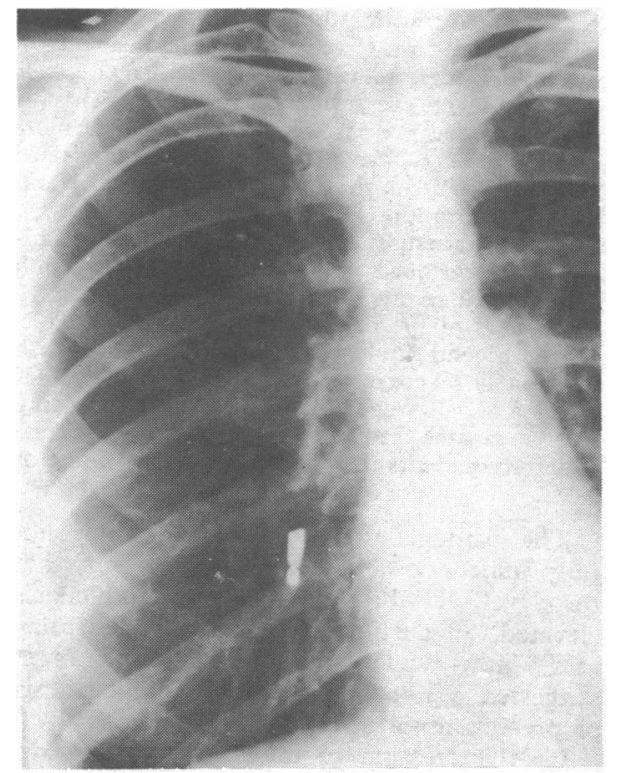

